Of patients undergoing resection for bronchial carcinoma, $41 \%$ may thus expect to survive for more than three years; and the five-year survival rate was $32.6 \%$. Most patients doomed to a recurrence develop it within 12 months, and the great majority within two years. Patients who are well two years after operation are more likely to die of other natural causes than of metastasis. Of the five-year survivors five originally had adenocarcinomas, seven were anaplastic, and all the rest squamous.

\section{Palliative Measures}

Deep $x$-ray therapy is indicated as a palliative measure for (1) inoperable anaplastic growths, especially in patients under 45 ; (2) mediastinal obstruction ; (3) Pancoast syndrome; (4) dysphagia; and (5) bone involvement by either primary or secondary growths. It is also of value in diminishing an exhausting cough or reducing unusually brisk or frequent haemoptyses. It is absolutely contraindicated if the growth has already disseminated, if the neoplasm is an adenocarcinoma, if sepsis is present in the lung, or if the patient is already short of breath because of emphysema.

A full course of therapeutic deep $x$-irradiation taxes a patient at least as much as does a pneumonectomy.

Intractable chest-wall pain is sometimes completely relieved by intercostal neurectomy; but when growth erodes the vertebral column or involves the brachial plexus cordotomy may be necessary. Infection is controlled by antibiotics, and pus in the pleural cavity is removed by aspiration. Only if a bronchopleural fistula is present should pus be drained surgically. Recurrent effusions are treated by aspiration, but occasionally are prevented by parietal pleurectomy.

My experience with chemotherapy has not been happy. Treatment with nitrogen mustard compounds is sometimes accompanied by diminution of the $x$-ray opacity and an improvement in general well-being and appetite. The former is generally due, I think, to the effect of penicillin and the latter to hydrocortisones both given with the cytotoxic drugs. On the other hand, damage to bone-marrow is always severe and sometimes uncontrollable.

Finally, may I make a plea for adequate drug palliation of the inoperable in the terminal stages of the disease? So much can be done for them and so little often is. The nausea associated with hepatic secondaries is mitigated by adequate dosage with promethazine theoclate (" avomine"), amiphenazole ("daptazole "), or pyridoxine ; appetite and a sense of general well-being is often at least partially restored by cortisone derivatives (such as $20 \mathrm{mg}$. of prednisolone) daily; agitation and anxiety are quieted by chlorpromazine; codeine and aspirin are often as effective drugs as any for pain, but pethidine, methadone, or heroin should never unnecessarily be withheld. Above all, dosage must be adequate to achieve relief. and there should be no hesitation in administering heroin even in doses up to $2 \mathrm{gr}$. $(0.13 \mathrm{~g}$.) where distress is great.

As you have seen from the results given here, it is not often given to doctors to cure : but we should not forget that it is always possible to relieve.

\section{Summary}

A plea is made for the application of effective preventive measures against bronchial carcinoma, now a major problem in public health.
The symptoms and treatment of bronchial carcinoma are described.

A series of 826 operations for lung cancer, performed by one surgeon, is reviewed. Of these, 570 involved pulmonary resection.

The importance of lung preservation in reducing both immediate and long-term mortality after pulmonary resection is stressed. A total of 299 pneumonectomies and 266 lobectomies were performed, with a hospital mortality of $5.6 \%$ and a five-year survival rate of $32.6 \%$.

\section{REFERENCES}

Auerbach, O., Gere, J. B., Forman, J. B., Petrick, T. G., Smolin, H. T. Muehsam, G." E Kassouny "D. Y and Stout A P. (1957). New Engl. j. Med., 256, 97.

Burford, T. H., Ferguson, T. B., and Spjut, H. J. (1958). J. thorac. Surg., 36, 316 .

Churchill, E. D., Sweet. R. H., Scannell, J. G., and Wilkins, E. W. (1958). Ibid., 36, 301.

Doll, R., and Hill, A. B. (1954). Brit. med. J., 1, 1451

Eastcoti (1956), Ibid., 2, 1071 .

Eastcott, D. F. (1956). Lancet, 1, 37.

Flavell, G. (1953). Brit. J. Tuberc., 47, 135.

(1956). Lancet. 1, 260.

Gifford, J. H., and Waddington, J. K. B. (1957). Brit. med. J., 1. 723

Hammond, E. C. (1958). Ibid., 2, 649.

Jones, J. C., Robinson, J. L., Meyer, B. W., and Motley, H. L. (1960). 'J thorac. Surg., 39, 144.

Ochsner, A. (1960). J. Amer. Geriat. Soc., 8, 159.

Price Thomas, C. (1952) Ann. roy. Coll. Surg. Engl., 11, 205.

Sellors, T. H. (1955). Brit. med. J., 1, 445.

Taylor, A. B. (1960). Thorax, 15, 3.

\section{UNEXPLAINED STEATORRHOEA IN THE SYNDROME OF HYPONATRAEMIA AND CARCINOMA OF BRONCHUS}

\author{
BY \\ PAUL TURNER,* M.B., B.S., B.Sc. \\ Late Senior House Officer \\ AND \\ ROGER WILLIAMS, M.D., M.R.C.P. \\ Lecturer in Medicine
}

From the Departments of Rheumatology and Medicine, Royal Free Hospital, London

The occurrence of hyponatraemia in patients with bronchial carcinoma was first reported by Winkler and Crankshaw (1938). Two further cases were described by Schwartz et al. (1957), who also noted that the low serum sodium level was associated with a high urinary sodium excretion. They found that the only effective way of raising the serum sodium to normal was to restrict the fluid intake, and postulated that the hyponatraemia was due to a sustained inappropriate secretion of antidiuretic hormone (A.D.H.). Roberts (1959) described a similar case, and Schwartz et al. (1960) studied another patient with this syndrome who was treated with nitrogen mustard with partial correction of the electrolyte disturbance. Rees et al. (1960) described the case of a patient with bronchial carcinoma and a low serum sodium level in whom amino-aciduria and increased phosphate excretion was found although the kidneys were histologically normal at necropsy. They suggested that an acquired renal tubular defect was responsible both for these changes and for the hyponatraemia, rather than excess A.D.H. activity. 
The purpose of this paper is to describe a further case of this syndrome which in addition showed a marked and progressive steatorrhoea.

\section{Case History}

A 42-year-old machine operator was admitted to the Royal Free Hospital in November, 1959, with a story of general ill-health for the preceding six months. He complained particularly of constipation and muscle weakness, and also described occasional episodes of sweating and faintness for a few minutes after a heavy meal. According to his wife the history was of longer duration, and she had noted changes in his personality with irritability, irresponsibility, and loss of libido since January, 1959.

On examination he was a sallow, wasted man with generalized light-brown pigmentation of the skin. The abdomen was distended. There was bilateral ptosis and both pupils were dilated and unreactive to light. His bloodpressure fluctuated between $120 / 80$ and $80 / 50 \mathrm{~mm}$. $\mathrm{Hg}$.

Initial Investigations.-The haemoglobin was $12.4 \mathrm{~g} . /$ $100 \mathrm{ml}$., white cell count 5,100/c.mm., and the E.S.R. $2 \mathrm{~mm}$. in the hour (Westergren). A fasting blood sugar was normal (67 mg./100 ml.). The serum electrolytes were: sodium 117 , potassium 4.2 , chloride 85 , bicarbonate 21 , magnesium $2 \mathrm{mEq} /$ litre respectively. The serum albumin was 5.5 and globulin $1.4 \mathrm{~g} . / 100 \mathrm{ml}$. The blood urea was $23 \mathrm{mg} . / 100 \mathrm{ml}$, and there was no proteinuria or glycosuria. C.S.F. examination was normal and $x$-ray films of the chest and skull showed no abnormality.

Further serum sodium estimations gave values varying between 117 and $121 \mathrm{mEq} / \mathrm{l}$. with a urinary sodium excretion of between 110 and $135 \mathrm{mEq} / 24$ hours.

\section{Subsequent Course}

The patient continued to lose weight and became progressively more cachectic with a grossly distended and tympanitic abdomen. His stools were noted to be light and bulky, and faecal fat estimations revealed a definite steatorrhoea with an average excretion of $10.7 \mathrm{~g}$. $/ 24$ hours over a three-day period. A barium-meal examination showed slow gastric emptying and a follow-through examination showed dilatation of the small bowel and flocculation consistent with steatorrhoea. The large bowel was also strikingly dilated and a barium enema disclosed narrowing of the sigmoid colon suggestive of malignancy. In view of this, and a persistently positive occult blood reaction in the stool, laparotomy was carried out on February 11, 1960, by Mr. George Qvist. This was done under a steroid cover of fluorohydrocortisone $3 \mathrm{mg}$. daily, which had been found to cause a definite rise in serum sodium level (see Metabolic Studies). At operation the dilatation of the bowel extended as far as the recto-sigmoid junction, but no neoplasm was found. The mesenteric lacteals were engorged with chyle despite the patient's pre-operative fast of 18 hours, and the mesenteric lymph nodes appeared slightly enlarged. Biopsies were taken from the jejunum and lymph node but did not help in diagnosis. The lymph nodes showed chronic lymphadenitis and the jejunum submucosal oedema only.

After laparotomy the patient's condition continued to deteriorate, with loss of weight and severe abdominal pain and distension. Despite the negative surgical biopsy the most likely diagnosis appeared to be a reticulosis involving the intestinal lymph nodes, and after discontinuing fluorohydrocortisone he was treated with cortisone $200 \mathrm{mg}$. daily. This failed to produce any improvement in the steatorrhoea as judged by estimations of faecal fat or in his general clinical condition. The serum sodium level fell again, and after six weeks the cortisone was discontinued and fluorohydrocortisone $2 \mathrm{mg}$. daily recommenced. The serum sodium level then rose to normal over a 21-day period, but clinically there was no improvement. His mental status was unchanged, and though he was never completely disorientated in time and space he was often confused and aggressive, and secreted food and drugs in his locker. Finally, on May 13, a further chest $x$-ray examination revealed a collapse of the left lower lobe with a probable mass at the hilum. This was confirmed by tomography and a diagnosis of carcinoma of the lung was made, although there were still no signs referable to the chest. He lapsed into coma and died two weeks later, six months after admission.

Necropsy Findings (Dr. Isobel P. Beswick).-There was an anaplastic oat-cell carcinoma arising from the left lower lobe bronchus and occluding it, the lung beyond showing bronchopneumonia and multiple abscess formation. Carcinomatous metastases were present in the mediastinal lymph nodes and had attained a large size in the tracheo-bronchial nodes. No other metastases were found. The thoracic duct was compressed between the vertebral column and lymph nodes containing metastases at the level of the fourth thoracic vertebra, and also by a mass of nodes behind the hilum of the right lung. There was no dilatation of the duct, which was, in fact, rather small and inconspicuous. The mesenteric lymph nodes were small and golden yellow in colour, microscopy showing a large quantity of fat in the hyperplastic sinus-lining cells. The intestines were macroscopically normal apart from marked dilatation, but on microscopy there was a mild chronic inflammation of the mucosa and muscularis throughout the gut. There was considerable oedema of the jejunal villi, and frozen sections showed sudanophil material in them. lying in phagocytes and in free globules. The kidneys were of normal size and showed no abnormality on section. There were no secondary deposits in the brain, and the hypothalamus and pituitary region were normal.

\section{Metabolic Studies Sodium and Water Metabolism}

Effects of Altering Sodium and Fluid Intake (Fig. 1).The patient's fluid intake was reduced to $500 \mathrm{ml}$./day for four days. during which the sodium intake was $22 \mathrm{mEq} /$ day. After this the serum sodium concentration rose from 118 to $140 \mathrm{mEq} / \mathrm{l}$. The sodium intake was then increased to $660 \mathrm{mEq} /$ day by mouth, and the fluid intake to $1.100 \mathrm{ml} . /$ day. During the first 48 hours on this regime the serum sodium level fell from 140 to $128 \mathrm{mEq} / \mathrm{l}$. Then I litre of normal saline (154 $\mathrm{mEq}$ of sodium) was given intravenously over six hours with a marked increase in urinary sodium
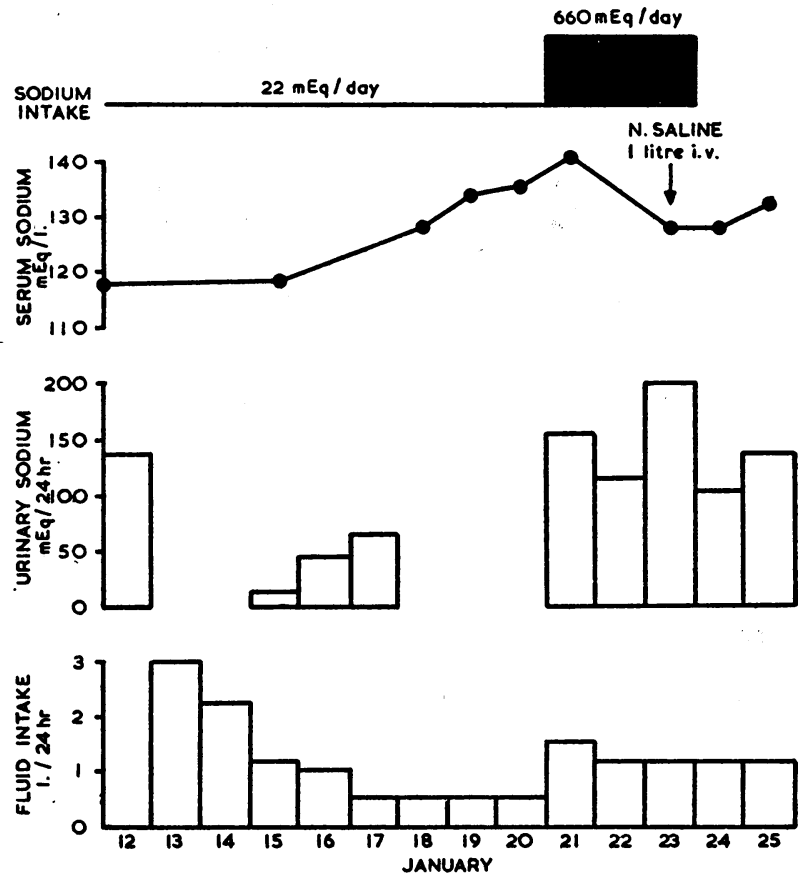

FIG. 1.-Changes in serum and urinary sodium levels in response to fluid restriction and increased sodium intake. 
excretion (195 mEq/24 hours) and only a slight rise in serum sodium concentration from 128 to $132 \mathrm{mEq} / \mathrm{l}$. on the second day.

Effects of Adrenocortical Steroids (Fig. 2).-Fluorohydrocortisone $3 \mathrm{mg}$. daily had been started before operation and was continued for a further 14 days with the patient on a standard ward diet containing about $10 \mathrm{~g}$. of sodium chloride $(170 \mathrm{mEq}$ of sodium) daily. This resulted in a rise

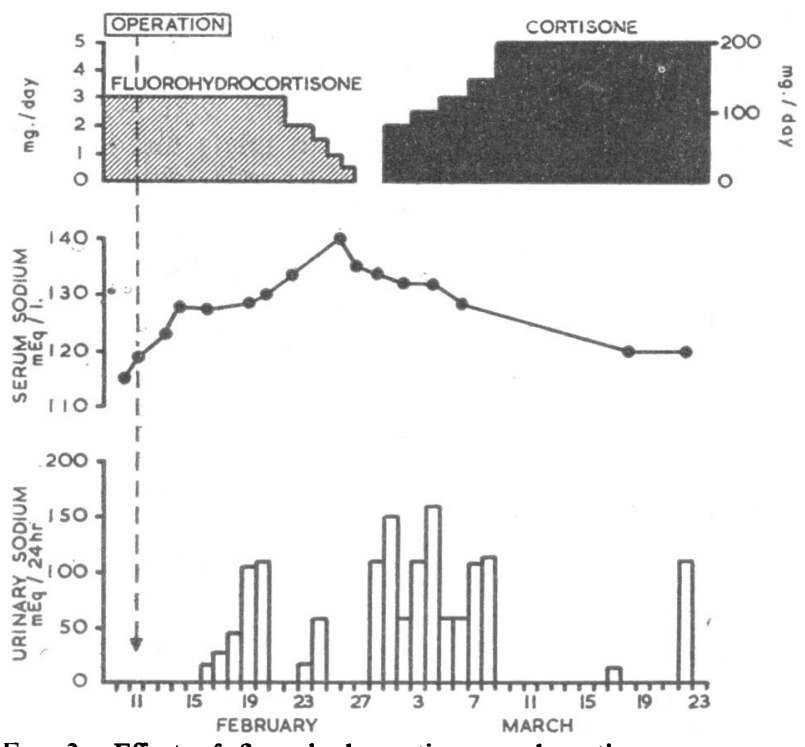

FIG. 2.--Effect of fluorohydrocortisone and cortisone on serum and urinary sodium levels.

of serum sodium from 117 to $140 \mathrm{mEq} / \mathrm{l}$. The fluorohydrocortisone was then discontinued and cortisone acetate 200 mg. was given by mouth with the patient on the same ward diet. The serum sodium fell to $120 \mathrm{mEq} / \mathrm{l}$. over 14 days. Subsequently deoxycortone acetate was given in a dose of $5 \mathrm{mg}$. intramuscularly for 12 days. This produced only a slight rise in serum sodium from 120 to $125 \mathrm{mEq} / 1$.

\section{Endocrine and Renal Function}

The urinary 17-hydroxycorticosteroid excretion was 13.6 mg. $/ 24$ hours and there was a normal response to intravenous A.C.T.H. stimulation (25 units over eight hours), the level rising to $54 \mathrm{mg} . / 24$ hours. The 24 -hour excretion of F.S.H. (Dr. I. Somerville) was less than 5 mouse units in 24 hours. A radioactive iodine uptake was normal.

Biological assay of antidiuretic hormone was attempted, but the patient had a chronic urinary infection which interfered with the assay. An A.D.H. stimulation test was done in which a diuresis was produced by giving $1,250 \mathrm{ml}$. of water at zero time, and nicotine $0.5 \mathrm{mg}$. and $1 \mathrm{mg}$. given intravenously at two and two and a half hours afterwards. This dose of nicotine is sufficient to produce unpleasant symptoms, and normally the rate of urine flow falls to $1 \mathrm{ml}$./ minute or less and does not return to the control rate for one and a half hours. In the present case the urine output did not fall below $2 \mathrm{ml}$./minute and had returned to the control rate within one hour.

Tests of renal function showed that the patient could dilute normally to a specific gravity of 1002 after a water load of 1 litre, but could not concentrate above 1015 after fluid deprivation for 18 hours. No abnormal amino-acids were found in the urine by chromatographic methods. Urinary acidification was studied by giving $5 \mathrm{~g}$. of ammonium chloride at zero time in 1 litre of water, and collecting urine at two, four, and six hours afterwards. Normally the urine should acidify to a $p \mathrm{H}$ below 5.3 and contain more than $1.5 \mathrm{mEq} /$ hour of ammonia in at least one specimen. In this case the lowest $p \mathrm{H}$ recorded was 6.8 , but an ammonium output of $5.5 \mathrm{mEq} /$ hour was reached in this specimen.

\section{Intestinal Absorption}

The serum calcium on admission was $9.1 \mathrm{mg} . / 100 \mathrm{ml}$., with a serum phosphate of $4 \mathrm{mg} . / 100 \mathrm{ml}$. Five months later the serum calcium had fallen to $8.5 \mathrm{mg} . / 100 \mathrm{ml}$. The serum albumin similarly fell during the period of observation $(5.5 \mathrm{~g}$. to $4.4 \mathrm{~g}$. $/ 100 \mathrm{ml}$.) and the ${ }^{131} \mathrm{I}$-labelled polyvinylpyrrolidone test of intestinal protein loss was abnormal, $2.5 \%$ of the administered intravenous dose appearing in the stools over a period of the next four days (normal up to $1.5 \%$ : Gordon. 1959).

There was slight anaemia, haemoglobin values varying between 11.8 and $13.7 \mathrm{~g} . / 100 \mathrm{ml}$. Sternal-marrow examination showed normoblastic erythropoiesis. The serum vitamin $B_{12}$ level was $875 \mu \mu \mathrm{g} . / \mathrm{ml}$. and absorption, using the Schilling technique, within normal limits. Folic-acid absorption was studied on two occasions. On January 23 the 24-hour excretion in the urine after $5 \mathrm{mg}$. of folic acid subcutaneously was $4 \mathrm{mg}$. and after an oral dose $5 \mathrm{mg}$., but on February 26 the corresponding levels were $4.5 \mathrm{mg}$. and $1.1 \mathrm{mg}$., showing marked impairment of absorption.

Xylose absorption also showed progressive impairment. On January $144.9 \mathrm{~g}$. of xylose was excreted in the urine in five hours after an oral dose of $25 \mathrm{~g}$., whereas on March 30 the urinary excretion was $3.8 \mathrm{~g}$. in five hours (the normal being not less than $4.2 \mathrm{~g}$.). A glucose-tolerance test gave a fasting level of $64 \mathrm{mg} . / 100 \mathrm{ml}$., with readings at halfhourly intervals after $50 \mathrm{~g}$. of glucose of $100,95,42,63$, and $68 \mathrm{mg} . / 100 \mathrm{ml}$.

Faecal fat estimations were almost always above normal, but varied considerably. There appeared to be some correlation with the serum sodium levels, in that the highest faecal fat recorded, $35 \mathrm{~g}$. $/ 24$ hours, occurred when the serum sodium was $120 \mathrm{mEq} / \mathrm{l}$, and the lowest, $2.4 \mathrm{~g}$. $/ 24$ hours, when the serum sodium had been raised by fluorohydrocortisone to $140 \mathrm{mEq} / 1$.

\section{Discussion}

The two main points of interest in this case are the nature of the hyponatraemia and the causation of the steatorrhoea. It might be suggested that hyponatraemia was simply due to the steatorrhoea. Mickerson (1960) described two cases of steatorrhoea with serum sodium concentrations of $130 \mathrm{mEq} /$ litre or less in which there was some evidence of adrenocortical failure. He thought that this was secondary to anterior pituitary deficiency. In our patient, however, adrenal function was normal. Measurements of faecal sodium were within normal limits, excluding another possibility that the hyponatraemia was the result of excessive loss through the gut. It seems more probable, therefore, that the hyponatraemia was related to the carcinoma of the bronchus, and our findings in relation to the effect of fluid deprivation and salt loading are similar to those described by Schwartz et al. $(1957,1960)$, who postulated a sustained inappropriate secretion of A.D.H. In these cases and in that described by Roberts (1959) there was no evidence of renal impairment. In the case reported by Rees et al. (1960), however, there were marked changes in renal function with glycosuria, ketonuria, and aminoaciduria, although the kidneys were normal histologically. The only abnormality in the present case was slight reduction in concentrating power, and it appears much more likeıy that the hyponatraemia was due to excess A.D.H. rather than to an acquired renal tubular defect as suggested by Rees and his colleagues.

The same metabolic disturbance may occur occasionally in tuberculous meningitis and in cerebral tumours or vascular disease involving the hypothalamic region, a syndrome which has been called "cerebral 
salt wasting." Recent cases have been investigated by Golberg and Handier (1960) and by Carter et al. (1961), who concluded that the hyponatraemia in this syndrome, as in carcinoma of the bronchus, was due to excess A.D.H. production. Experimentally a very similar state has been induced in healthy persons and dogs by administration of repeated doses of vasopressin (Leaf and Mamby, 1952 ; Leaf et al., 1953). The apparently high urinary sodium excretion is probably related to expansion of the extracellular fluid volume, with resulting depression of aldosterone secretion (Bartter et al., 1956). Stewart and Rourke (1942) were able to induce sodium loss simply by acute overloading with water without administering antidiuretic hormone.

The reason for the increased A.D.H. production remains to be found. In cerebral disease there may be direct irritation of the posterior pituitary and hypothalamic regions. Possibly in carcinoma of the bronchus the stimulation may be reflex in origin from thoracic vascular receptors. Numerous workers have shown that pressure changes in the great veins of the thorax result in changes in salt and water balance probably through neuronal circuits making contact with the posterior part of the pituitary gland concerned with the production of A.D.H. and at the same time with the region near the pineal gland, which is believed to be involved in aldosterone liberation (Farrell, 1959).

The cause of the mental changes in this case is obscure. They were in fact the first symptoms noticed and were present at least 16 months before there was radiological evidence of carcinoma. Psychological testing and electroencephalography suggested that he had a confusional state rather than a dementia, consistent with a biochemical disturbance. It seems unlikely that this was due to simple water intoxication, for there was no improvement when the serum sodium rose to normal with water deprivation. In one of the cases of cerebral salt wasting described by Golberg and Handler (1960) the neurological symptoms did improve with raising of the serum sodium level. In the present case in addition to the mental symptoms there were definite neurological signs with bilateral ptosis and fixed dilated pupils. It is to be noted, however, that similar neurological signs have been described in carcinoma of the bronchus without hyponatraemia (Brain and Henson, 1958).

The most difficult finding to explain was the severe steatorrhoea. This was also of interest, for it appeared to be progressive, both xylose and folic-acid-absorption tests becoming abnormal during the course of the admission. There is no account of steatorrhoea in previous cases of hyponatraemia and carcinoma of the bronchus although it is possible that it was present in one of the patients (Schwartz et al., 1957) who had severe diarrhoea terminally. In this patient, however, widespread abdominal metastases were found at necropsy.

We could find no definite cause for the steatorrhoea in the present case. The presence of normal jejunal villi excludes idiopathic steatorrhoea. There were no lesions in the pancreas or its duct. It cannot be attributed to lymphatic blockage, for, although the thoracic duct was involved by tumour in the thorax, it was not dilated and there were no uther signs of obstruction such as chylous effusion. Abnormal gut flora, perhaps secondary to gut dilatation, is a possibility, although the finding of normal vitamin- $B_{12}$ absorption is against this mechanism. It is to be noted that at necropsy both vagi were involved by tumour, and this might explain the gut dilatation which was such a striking feature; but dilatation by itself should not cause steatorrhoea. Weaver and Balme (1960) described 17 cases of bronchial carcinoma presenting with gastro-intestinal symptoms, usually due to duodenal or gastric ulcers, and suggested that irritation of a vagus nerve in the thorax by neoplasm might be responsible.

The severity of the steatorrhoea as measured by daily faecal fat excretion appeared to vary with the serum sodium level, and it is tempting to relate the defective bowel function with the hyponatraemia, although the mechanism is unknown.

\section{Summary}

A further case is described of hyponatraemia and high urinary sodium excretion in association with carcinoma of the bronchus. The most likely cause appeared to be increased secretion of antidiuretic hormone, and with fluid deprivation the serum sodium rose to normal.

The patient presented with neurological symptoms 16 months before the carcinoma was discovered, and at no time were there clinical signs referable to the chest. An unexplained finding was the presence of severe and progressive steatorrhoea which appeared to be related to the metabolic disturbance.

We thank Dr. A. T. Richardson for his permission to publish this case report ; Professor $\mathbf{H}$. de Wardener for his helpful advice; and Dr. I. P. Beswick for the histological report.

\section{REFERENCES}

Bartter, F. C., Liddle, G. W., Duncan, L. E., jun., Barber, J. K. and DeLea, C. (1956). J. clin. Invest., 35, 1306.

Brain, W. R., and Henson, R. A. (1958). Lancet, 2, 971

Carter, N. W., Rector, F. C., and Seldin, D. W. (1961). New Engl. J. Med., 264, $6 \dot{7}$.

Farrell, G. (1959). Endocrinology, 65, 239.

Golberg, M.. and Handler, J. S. (1960). New Engl. J. Med., 263 1037 .

Gordon, R. S. (1959). Lancet, 1, 325

Leaf, A., Bartter, F. C., Santos, R. F., and Wrong, O. (1953). J. clin. Invest., 32, 868 .

and Mamby, A. R. (1952). Ibid., 31, 54.

Rees, J. R., Rosalki, S. B., and Maclean, A. D. W. (1960) Lancet, 2, 1005.

Roberts, H. J. (1959). Ann. intern. Med., 51, 1420

Schwartz, W. B., Bennett, W., Curelop, S., and Bartter, F. C. (1957). A Amer. J. Med., 23, 529. Tassel, D., and Bartter, F. C. (1960). New Engl. J. Med. 262, 743 .

Stewart, J. D., and Rourke, G. M. (1942). J. clin. Invest., 21 , 197.

Weaver, E. J. M., and Balme, R. H. (1960). Brit. med. J., 1, 1543

Winkler, A. W., and Crankshaw, O. F. (1938). J. clin. Invest., 17, 1

Janata, an Indian journal, has devoted a special number, November, 1961-to problems of health. The editorial says that it hopes the special issue will "give its readers a comprehensive picture of the efforts that are being made and of the problems yet to be tackled. The knowledge, it is earnestly hoped, will inspire action and enable the country to wage a resolute war against disease." Many of the articles are devoted to health and social legislation in countries other than India, while Indian writers and doctors cover subjects such as population and its control, and medical education in India. Dr. V. N. Rajan, directorgeneral of the Employees' State Insurance Corporation, contributes an outline of "Awakening of Social Consciousness in India "-the record of a decade. Janata is published at National House, 6 Tulloch Road, Bombay 1, India. 